\title{
MULTIPLE SINGULAR INTEGRALS AND MAXIMAL OPERATORS WITH MIXED HOMOGENEITY ALONG COMPOUND SURFACES
}

\author{
FENG LIU AND DAIQING ZHANG
}

\begin{abstract}
In this paper we present the $L^{p}$ mapping properties for a class of multiple singular integral operators along polynomial compound surfaces provided that the integral kernels are given by the radial function $h \in \Delta_{\gamma}$ (or $h \in U_{\gamma}$ ) for some $\gamma>1$ and the sphere function $\Omega \in$ $\tilde{\mathscr{F}}_{\beta}\left(S^{m-1} \times S^{n-1}\right)$ for some $\beta>0$, which is distinct from $L\left(\log ^{+} L\right)^{2}\left(S^{m-1} \times S^{n-1}\right)$. In addition, the $L^{p}$ bounds for the related maximal operators are also established. Some previous results are greatly extended and improved.
\end{abstract}

Mathematics subject classification (2010): 42B20, 42B25.

Keywords and phrases: Singular integrals, maximal operators, mixed homogeneity, product domains.

\section{REFERENCES}

[1] A. Al-Salman, Parabolic Marcinkiewicz integrals along surfaces on product domains, Acta. Math. Sin. (Engl. Ser.), 27, (2011), 1-18.

[2] A. Al-S Alman, Maximal operators with rough kernels on product domains, J. Math. Anal. Appl., 311, (2005), 338-351.

[3] A. Al-Salman, A note on parabolic Marcinkiewicz integrals along surfaces, Proc. A Razmadze Math. Inst., 154, (2010), 21-36.

[4] A. Al-Salman, Marcinkiewicz integrals along subvarieties on product domains, Inter. J. Math. Math. Sci., 72, (2004), 4001-4011.

[5] A. Al-Salman, H. Al-QASSEM AND Y. PAn, Singular integrals on product domains, Indiana Univ. Math. J., 55, (2006), 369-387.

[6] K. Al-Balush And A. Al-Salman, Certain $L^{p}$ bounds for rough singular integrals, J. Math. Inequa., 8, (2014), 803-822.

[7] H. AL-QASSEM AND Y. PAN, A class of maximal operators related to rough singular integrals on product domains, J. Integr. Equa. Appl., 17, (2005), 331-356.

[8] J. CHEN, $L^{p}$ boundedness of singular integrals on product domains, Sci. China (Ser. A), 44, (2001), 681-689.

[9] L. CHen AND H. LE, Singular integrals with mixed homogeneity in product spaces, Math. Inequal. Appl., 14, (2011), 155-172.

[10] Y. DING, A note on a class of rough maximal operators on product domains, J. Math. Anal. Appl., 232, (1999), 222-228.

[11] J. DuOANDikoEtXeA, Multiple singular integrals and maximal functions along hypersurfaces, Ann. Inst. Fourier Gronble, 36, (1986), 185-206.

[12] E. FABES AND N. REVIÉRE, Singular integrals with mixed homogenity, Studia Math., 27, (1966), $19-38$.

[13] D. FAN AND Y. PAN, Singular integral operators with rough kernels supported by subvarieties, Amer. J. Math., 119, (1997), 799-839.

[14] R. FefFerman, Singular integrals on product domains, Bull. Amer. Math. Soc., 4, (1981), 195-201.

[15] F. FefFerman And E. M. Stein, Singular integrals on product domains, Adv. Math., 45, (1982), $117-143$

[16] L. GRAFAKOS AND A. STEFANOV, $L^{p}$ bounds for singular integrals and maximal singular integrals with rough kernels, Indiana Univ. Math. J., 47, (1998), 455-469. 
[17] S. LAN, F. LIU AND H. WU, Singular integrals and Marcinkiewicz integrals along compound curves on product domains, Adv. Math. (China), 43, 6 (2014), 921-941.

[18] Z. LI, B. MA AND H. WU, Maximal operators and singular integrals with non-isotropic dilation on product domains, Acta. Math. Sin. (Engl. Ser.), 26, (2010), 1847-1864.

[19] F. LiU AND H. WU, Multiple singular integrals and Marcinkiewicz integrals with mixed homogeneity along surfaces, J. Inequal. Appl., 2012, 189 (2012), 1-23.

[20] F. LIU AND H. WU, Rough singular integrals and maximal operators with mixed homogeneity along compound curves, Math. Nachr., 287, (2014), 1166-1182.

[21] L. MA, D. FAN AND H. WU, $L^{p}$ bounds for singular integrals with rough kernels on product domains, Acta. Math. Sin. (Engl. Ser.), 28, (2012), 133-144.

[22] E. M. STEIN, Harmonic Analysis: Real-variable methods, orthogonality and oscillatory integral, Princeton University Press, Princeton, 1993.

[23] T. WaLsh, On the function of Marcinkiewicz, Studia Math., 44, (1972), 203-217.

[24] H. WU, General Littlewood-Paley functions and singular integral operators on product spaces, Math. Nachr., 279, (2006), 431-444.

[25] H. WU AND S. YANG, On multiple singular integrals along polynomial curves with rough kernels, Acta Math Sin (Engl Ser), 24, (2008), 177-184.

[26] Y. YING, A note on singular integral operators on product domains, J. Math. Study (in Chinese), 32, (1999), 264-271. 